\title{
Experimental Approaches to the Production and Perception of Prosody
}

\author{
Joseph Butler, Marisa Cruz and Marina Vigário \\ University of Lisbon, Portugal
}

This Special Issue brings together a selection of papers orally presented at the conference Phonetics and Phonology in Iberia (PaPI), held in Lisbon in 2013 (labfon.letras.ulisboa.pt/papi2013). For 10 years the $P a P I$ conferences have been a highly productive setting for the sharing and discussion of investigation within phonology and phonetics and their interactions, and have undoubtedly played their part in the development of experimental work in the field of prosody (see in particular Frota, Vigário, \& Freitas, 2005; Prieto, Mascaró, \& Solé, 2007; Romero \& Riera, in press; Vigário, Frota, \& Freitas, 2009).

Prosodic research has witnessed remarkable progress in the last few decades. The limits of the field are pushed farther constantly as new investigations appear, powered by more elaborate experimental methods, new technology and resources, innovative bridges promoting knowledge transfer across disciplines, increasingly sophisticated theoretical models and a continuously evolving set of questions.

This volume also reflects the productivity of experimental approaches to prosody. It compiles work addressing a range of questions that are of current interest in prosody, exploring topics such as the phonetic exponents of rhythm and information structure in language development, languageparticular factors in the perception of word stress, social and situational factors underlying speakers' pitch accent selection and the phonology of fine grain phonetic variation in accent realization. All of the papers follow a laboratory-based approach to phonology and a variety of experimental methods are employed to elicit controlled production data as well as to investigate perception, including tasks involving picture-matching and other types of interactive games, discourse completion, ABX discrimination, sequence recall and context matching acceptability judgements.

Two papers investigate prosodic development, one contrasting child and adult Dutch monolinguals and the other comparing English and Spanish monolingual and simultaneous EnglishSpanish bilingual children.

In the paper 'Quiet is the New Loud: Pausing and Focus in Child and Adult Dutch', Romøren and Chen report on an experiment that tested the use of pauses to signal focused material in Dutch, both in adults and in 4 to 5 year-olds. Adults tend to use accent and post-focal deaccentuation to mark focus. However, previous research has shown that adult speakers of Dutch also use pauses 
before focus and that children at this age do not fully master adult focus prosody (Chen, 2007, 2011). The experiment elicited sentences with focus structure by means of a picture-matching game and combining controlled speech contexts with wh-questions. Results showed a significant difference in pause durations before focal and non-focal targets, the pause being longer in the former, both in adults and in children's productions. Nevertheless, the use of pauses was found to be more systematic in children. The authors interpret this difference as a consequence of the child's stage in language development. Research on the development of information structure signalling, using controlled and efficient elicitation methods, is fairly rare, and to our knowledge this is the first investigation on pausing as a means to cue focus in child speech.

In the paper by Schmidt and Post ('The Development of Prosodic Features and their Contribution to Rhythm Production in Simultaneous Bilinguals'), the impact of bilingualism in terms of facilitory and inhibitory effects are investigated in relation to the acquisition of prosodic features. Focusing on phrase-final lengthening and accentuation in English and Spanish, two areas where the rhythmic differences between the two languages manifest, the authors demonstrate that the two languages can be rhythmically separated at 4 years, and clearly separable by 6 years of age, and that bilinguals have an advantage over monolinguals in the prosodic acquisition of the structurally more complex language (English). Overall comparison with monolinguals showed that bilinguals have an advantage in their development towards obtaining adult-like structures. As claimed by the authors, these findings suggest that these advantages are the result of the greater variability that the child is presented with due to both dual language input and dual language production, which require the child to develop more advanced motor control to produce a greater range of productions, and perhaps more stable mental representations extracted from the dual language input. This research provides new material, coming from phrase level prosody to the much debated question of whether bilinguals have enhanced language skills and to what extent bilinguals have an advantage over monolinguals in language development (see Costa \& Sebastián-Gallés, 2014, for a recent overview of the matter).

The contribution by Correia, Butler, Vigário and Frota ("A Stress "Deafness" Effect in European Portuguese') explores the specific properties of a particular language, European Portuguese (EP), towards the understanding of the precise factors that result in the so-called stress 'deafness' effect, a phenomenon not yet fully understood, that is found in languages like French and is characterized by listeners' poor ability in perceiving word stress contrasts. In the interest of comparability, Correia and colleagues strictly follow the methodology used by Dupoux and colleagues in the study of the perception of stress in several languages with variable or fixed stress (Dupoux, Pallier, Sebastián, \& Mehler, 1997; Dupoux, Peperkamp, \& Sebastián-Gallés, 2001; Peperkamp, Vendelin, \& Dupoux, 2010). EP has variable stress - like Spanish, but unlike French - and is further characterized by vowel reduction (like English) and a low covariance of pitch accents and word stress, duration being the main acoustic correlate of word stress. A series of experiments was conducted where subjects were required either to discriminate or to recall sequences of pseudo words with stress or phoneme contrasts, both in nuclear and post-nuclear positions. Overall, the results show that EP subjects rely more on vowel quality cues for stress than on suprasegmental cues, such as duration and pitch, since, in the absence of vowel reduction, EP listeners exhibit a stress 'deafness' effect analogous to French listeners. This research shows that stress 'deafness' effects are not just a consequence of a predictable stress grammar (contrary to proposals by Dupoux and colleagues). The authors also conclude that these findings dismiss the claim for a universal prosodic-based perception of word stress (Ortega-Llebaria, Vanrell, \& Prieto, 2010), and point instead to a language-sensitive mechanism in word stress perception.

Three papers of this volume investigate different topics related to pitch accent grammar. In 'Vocative Intonation Preferences are Sensitive to Politeness Factors', Borràs-Comes, Sichel-Bazin 
and Prieto address the questions of how sociopragmatic and situational factors, such as power or social distance and physical distance or insistence, respectively, constrain the selection of different types of pitch contours used for expressing vocatives in Central Catalan and how the use of different vocative contours may relate to different politeness strategies (Brown \& Levinson, 1987). First, a controlled production experiment was conducted, using a Discourse Completion Task. The results suggest that speakers tend to use one of three contours previously reported in the literature ( $\mathrm{L}^{*} \mathrm{H} \%, \mathrm{~L}+\mathrm{H}^{*} \mathrm{HL} \%$ and $\mathrm{L}+\mathrm{H}^{*} ! \mathrm{H} \%$ ), but the choice of a given contour is primarily constrained by power and/or social distance. Second, a perception study assessed the acceptability ratings on the appropriateness match between a set of vocative contours and a previous discourse context. The results of both experiments converge towards the relevance of sociopragmatic and situational factors in the use of Catalan vocative intonation. Adopting the taxonomic tools of politeness theory, a proposal is made for a three-way classification of Central Catalan vocative contours into different types of politeness strategy: negative politeness $\left(\mathrm{L}^{*} \mathrm{H} \%\right)$, bald on-record politeness $\left(\mathrm{L}+\mathrm{H}^{*} \mathrm{HL} \%\right)$ and positive politeness $\left(\mathrm{L}+\mathrm{H}^{*} ! \mathrm{H} \%\right)$. This paper opens a window to the study of the role of politeness factors in intonational meaning in other types of speech acts, a topic that has not previously attracted the attention of scholars following a laboratory phonology approach and using a well-defined model for tonal analysis such as that of Intonational Phonology (Gussenhoven, 2004; Ladd, 2008, and references therein).

As in other areas of speech, very subtle distinctions in tonal realization, such as the exact alignment of tones with respect to the segmental string, may either signal different phonological categories or constitute mere instances of phonetic variation - be it free, determined by phonetic or phonological factors or dependent on the speaker or other variables - without impact on the meaning associated to the melody. The last two papers of this volume bear on the phonological status of subtle but systematic differences in the realization of tonal categories, one focusing on production data and the other on perception.

In Baltazani and Kainada's paper ('Drifting Without an Anchor: How Pitch Accents Withstand Vowel Loss') the authors investigate the effect of vowel deletion on tonal alignment. Vowel deletion is an optional process that affects stressless vowels in Ipiros Greek. When post-tonic vowels are deleted, the peak of the pre-nuclear pitch accent $\mathrm{L}^{*+\mathrm{H}}$ is left without its natural phonological anchor. The authors test a number of hypotheses about the possible impact of vowel deletion on peak alignment by conducting a carefully controlled production experiment. The timing of the tonal events with respect to the segmental surfacing string was measured in words exhibiting three different patterns: (i) a pre-nuclear accent $\mathrm{L}^{*}+\mathrm{H}$ and no post-tonic vowel deletion; (ii) a pre-nuclear accent $\mathrm{L}^{*}+\mathrm{H}$ and the deletion of the post-tonic vowel ( $\mathrm{L}^{*}+\mathrm{Hdel}$ ); (iii) a nuclear accent $\mathrm{L}+\mathrm{H}^{*}$. The results show that when vowel deletion occurs the peak of $\mathrm{L}^{*}+\mathrm{H}$ aligns earlier than when the post-tonic vowel is present. However, the timing differences in the alignment of the peak of $\mathrm{L}^{*}+\mathrm{Hdel}$ and $\mathrm{L}+\mathrm{H}^{*}$ remain statistically significant. The authors conclude that the early placement of the peak as a consequence of vowel deletion is a phonetic phenomenon, which does not result in the neutralization of the phonological contrast between $\mathrm{L}^{*}+\mathrm{H}$ and $\mathrm{L}+\mathrm{H}^{*}$. This paper contributes to the understanding of the principles that govern text-tune association, and the factors that may condition the phonetic implementation of tonal categories. In addition, it adds to the knowledge of the dialectal variation in Greek prosody, a matter scarcely investigated to date.

Ritter and Grice ('The Role of Tonal Onglides in German Nuclear Pitch Accents') examine the relevance of the tonal onglide (i.e., the pitch movement leading to the tonal target on the accented syllable) in distinguishing given/non-contrastive and new/contrastive pragmatic meaning in German. Investigating this topic is especially welcome because different interpretations are found among researchers who work on German intonation as to the phonological status of the pitch 
movement before the stressed syllable. Using a perception experiment with resynthesized contours, Ritter and Grice tested whether listeners are able to distinguish between given/noncontrastive and new/contrastive meaning when only presented with the tonal onglide. From their results, the authors conclude that, rather than being merely a phonetic detail, the leading tone evident in German has a functional role as part of the nuclear contour, and that information that is important in terms of pragmatic interpretation is carried by the pitch movement occurring before the accentual syllable. By showing that the pitch movement leading to the stared tone is phonologically relevant, these results also support the models that incorporate both leading and trailing tones (Beckman, Hirschberg, \& Shattuck-Hufnagel, 2005) and not just trailing - that is, left-headed tones (Gussenhoven, 2005). Besides its contribution to the theoretical models of intonation, and the specific analysis of German accents, this paper also contributes to the establishment of suitable methods for determining the tonal phonological categories. Knowing how to interpret the phonetic variations in pitch linguistically has been a persistent, fundamental topic in intonation research and this is even more apparent at a time of rapid growth in the research on intonational variation across languages and dialects (e.g., Bruce, 2005; Frota \& Prieto, in press, and references therein; Gilles \& Peters, 2004; Nolan \& Post, 2014).

Before concluding, we wish to express our gratitude to the 22 reviewers who so generously agreed to collaborate with us in the selection of this set of papers and helped us to ensure the overall quality of the volume. A special thank you is also due to the Joint Editors of Language and Speech, Michael S Vitevitch and Joan A Sereno, and the Editorial Manager, Jim Polikoff, for the competent, responsive and pleasant collaboration at all stages of the preparation of this volume.

We believe this volume effectively celebrates 10 years of PaPI - Phonetics and Phonology in Iberia conferences. A new phase for these biennial scientific meetings is now beginning, as the next conference will happen for the first time outside the Iberian Peninsula. It is with great pleasure that we see PaPE - Phonetics and Phonology in Europe (as it is now called) hosted by the University of Cambridge in 2015 (www.ling.cam.ac.uk/pape).

\section{Acknowledgements}

This work was partially supported by grant PEst-OE/LIN/UI0214/2014 from the Foundation for Science and Technology (Portugal).

\section{References}

Beckman, M. E., Hirschberg, J., \& Shattuck-Hufnagel, S. (2005). The original ToBI system and the evolution of the ToBI framework. In S.-A. Jun (Ed.), Prosodic typology I: The phonology of intonation and phrasing (pp. 9-54). Oxford, UK: Oxford University Press.

Brown, P., \& Levinson, S. C. (1987). Politeness: Some universals in language use. Cambridge, UK: Cambridge University Press.

Bruce, G. (2005). Intonational prominence in varieties of Swedish revisited. In S.-A. Jun (Ed.), Prosodic typology I: The phonology of intonation and phrasing (pp. 410-429). Oxford, UK: Oxford University Press.

Chen, A. (2007). Intonational realisation of topic and focus by Dutch-acquiring 4- to-5-year-olds. Proceedings of the International Congress of Phonetic Sciences XCI, Saarbrücken, Germany, pp. 1553-1556.

Chen, A. (2011). The developmental path to phonological focus-marking in Dutch. In S. Frota (Ed.), Prosodic categories: Production, perception and comprehension. Studies in Natural Language and Linguistic Theory (pp. 93-110). Dordrecht, the Netherlands: Springer.

Costa, A., \& Sebastián-Gallés, N. (2014). How does the bilingual experience sculpt the brain? Nature Reviews Neuroscience, 15, 336-345. 
Dupoux, E., Pallier, C., Sebastian, N., \& Mehler, J. (1997). A destressing 'deafness' in French? Journal of Memory and Language, 36(3), 406-421.

Dupoux, E., Peperkamp, S., \& Sebastián-Gallés, N. (2001). A robust method to study stress 'deafness'. Journal of the Acoustical Society of America, 110(3), 1606-1618.

Frota, S., \& Prieto, P. (Eds.). (In press). Intonation in Romance. Oxford, UK: Oxford University Press.

Frota, S., Vigário, M., \& Freitas, M. J. (Eds.). (2005). Prosodies. Phonetics \& Phonology Series. Berlin/New York: Mouton de Gruyter.

Gilles, P., \& Peters, J. (2004). Regional variation in intonation. Tübingen, Germany: Niemeyer.

Gussenhoven, C. (2004). The phonology of tone and intonation. Cambridge, UK: Cambridge University Press.

Gussenhoven, C. (2005). Transcription of Dutch intonation. In S.-A. Jun (Ed.), Prosodic typology I: The phonology of intonation and phrasing (pp. 118-145). Oxford, UK: Oxford University Press.

Ladd, D. R. (2008). Intonational phonology. Cambridge, UK: Cambridge University Press.

Nolan, F., \& Post, B. (2014). IViE. In J. Durand, U. Gut \& G. Kristoffersen (Eds.), The Oxford handbook of corpus phonology (pp. 475-485). Oxford, UK: Oxford University Press.

Ortega-Llebaria, M., Vanrell, M. M., \& Prieto, P. (2010). Catalan speakers' perception of word stress in unaccented contexts. Journal of the Acoustical Society of America, 127(1), 462-471.

Peperkamp, S., Vendelin, I., \& Dupoux, E. (2010). Perception of predictable stress: A crosslinguistic investigation. Journal of Phonetics, 38(3), 422-430.

Prieto, P., Mascaró, J., \& Solé, M.-J. (Ed.). (2007). Segmental and prosodic issues in Romance Phonology. CILT Collection (Current Issues in Linguistic Theory, 282). Amsterdam, the Netherlands: John Benjamins.

Romero, J., \& Riera, M. (Eds.). (In press). The Phonetics-Phonology Interface: Representations and Methodologies. Amsterdam, the Netherlands: John Benjamins.

Vigário, M., Frota, S., \& Freitas, M. J. (Eds.). (2009). Phonetics and phonology: Interactions and interrelations. CILT Collection (Current Issues in Linguistic Theory, 306). Amsterdam, the Netherlands: John Benjamins. 